\section{ROLE OF CONSERVATIVE TREATMENT,STEROID INJECTION AND PLATELET RICH PLASMA IN PLANTAR FASCITIS- COMPARATIVE STUDY}

\section{Original Article}

\section{Orthopaedics}

\author{
Pradeep K Verma ${ }^{1}$, Rajesh Singh ${ }^{2}$ \\ 1 - Associate professor, Dept. of Orthopaedics, Shyam \\ Shah Medical College, Rewa, Madhya Pradesh \\ 2 - Senior resident, Dept. of Orthopaedics, Shyam Shah
}

Medical College, Rewa, Madhya Pradesh
Article submitted on: 05 March 2019 Article Accepted on: 09 March 2019

\begin{abstract}
Purpose: This study was undertaken to compare the three different modalities of non operative treatment: Non- invasive conservative methods, local Steroid injection therapy and local platelet rich plasma injection
\end{abstract}

Study Design: Prospective cohort study.

Methods: The study group comprised 90 patients divided into 3 groups each of 30 patients with a mean follow-up of 3 months.

Patients were assessed as per Visual Analogue Scale (VAS) and RolesMaudsley score at the start of treatment and then after 4 week and 12 week duration on follow up.

Statistical analysis used: SPSS for Windows (version 10.0) by the ChiSquare test

Results: The difference in the distribution of subjects belonging to either of the treatment modalities regarding the treatment outcome at I month and 3 month was found to be statistically insignificant.

Conclusion: As all three treatment modalities are at par on comparison of their treatment outcome it is better to go for conservative approach because this can save the patients from the complications of steroid therapy and PRP injection.
Keywords: Plantar fasciitis, conservative,steroid,platelet rich plasma 


\section{Introduction}

Plantar fasciitis is the most common cause of heel pain. The pain is often worst when first getting up in the morning, with typical hobbling downstairs, or when first getting up from a period of sitting-the typical start up pain and stiffness ${ }^{1}$. Today it is accepted that plantar fasciitis is a degenerative pathology rather than an inflammatory process ${ }^{2}$. Operative specimens show the histological evidence of degenerative changes in the plantar fascia and chronic inflammatory changes with or without fibroblastic proliferation ${ }^{2}$. The diagnosis is based on the typical history and the finding of localized tenderness in the medial calcaneal tubercle. Planter Fasciitis is considered a self limited condition. However, the long interval is frustrating for both patients and clinicians ${ }^{3}$. A conservative treatment method is usually preferred in the initial treatment of plantar fasciitis. The conservative treatment modalities described for plantar fascitis include changes in daily activities, orthoses, stretching, taping, and non-steroidal and anti-inflammatory drugs (NSAID) therapy ${ }^{4}$. Local injection modalities are commonly used secondary to conservative therapies in the treatment of patients who have resistant plantar fasciitis. The most preferred method of non-surgical plantar fasciitis treatment is local corticosteroid injection with or without the addition of a local anesthetic. Few randomized controlled trials have discussed the role of corticosteroids in the treatment of fasciitis ${ }^{5}$. Platelet-rich plasma (PRP), which is a natural concentrate of autologous growth factors, is now being widely tested in different fields of medicine for its possibilities in aiding the regeneration of tissue with low healing potential. Local injection of PRP is a new modality which has recently been discussed ${ }^{6}$ for the treatment of plantar fasciitis. In this study, the results of conservative treatment, local injection of PRP and corticosteroids in the treatment of plantar fasciitis are compared.

\section{Material And Methods}

A prospective study was done in period of 1 year from January 2018 till December 2018. Total 90 patients were taken up for the study that completed the follow-up. Patients by random sampling were divided in three groups. Group A as: Conservative group, Group B as Local Steroid Injections group and Group C as PRP injection, 30 patients in each. Consent was taken from all patients.

Inclusion Criteria: Patients in the age group of 18 to $65 \mathrm{y}$ with history of pain and tenderness in the sole of the foot, mostly under the heel, with standing or walking for period more than 1 month. Pain is often worst when first getting up in the morning, or when first getting up from period of sittingthe typical start up pain and stiffness. On examination tenderness in the heel on weight bearing and firm pressure with thumb by palpation especially at the medial side of heel.

Exclusion Criteria: Patients of plantar fasciitis in presence of other systemic disease like diabetes mellitus, rheumatoid arthritis, gout etc were excluded from study. Patients with history of trauma, Stress fracture calcaneum, and acute planter fascias rupture cases, patients with neurological pathology, Haglund's deformity cases and flat feet cases. Pregnant women, patient's less than 18 $\mathrm{y}$, and those with history of bleeding disorder or on anti coagulant therapy and cases of bilateral planter fasciitis were also excluded.
Group A- 30 Patients were started on NSAID's, Soft Insoles, Stretching and Contrast baths as following: Patients were prescribed paracetamaol $500 \mathrm{mg}$ twice daily for two week. Soft insoles were placed in the shoes of males. In females soft rubber sole cushioned footwear's were given. Both male and female patients were instructed not to stand or walk bare feet. Patients were simulataneously attended by a qualified physiotherapist who made them to do stretching exercises for planter fascia. They were asked to sit with the knees bent and heel flat on the floor and then to grab all five toes and pull them back toward the knee, hold for $30 \mathrm{sec}$ and repeat five times. They were also advised planter fascia stretches against the wall. Feet was placed against the wall and after gentle leaning forward slowly were asked to hold for $30 \mathrm{sec}$ and repeat the procedure five times. Contrast baths therapy was advised at home. Limb to be placed in a hotter bath at 40-42 Centigrade temperature for 3-4 min and then in a cold water at 15-20 Centigrade, for about $1 \mathrm{~min}$ alternatively with an instruction: to practice begin and end with the hotter bath.

Group B- 30 Patients were given local steroid injection in the form of 40 mg methyl prednisone mixed with $1 \mathrm{ml}$ of $2 \%$ lignocaine at weekly intervals up to three injections after subcutaneous sensitivity test of lignocaine in a sterile atmosphere i.e. minor OT after part preparation.

Group C- 30 patients were injected with $3 \mathrm{~mL}$ PRP after $1 \mathrm{~mL}$ of $2 \%$ lignocaine injection intervals after subcutaneous sensitivity test of lignocaine in a sterile atmosphere i.e. minor OT after part preparation

The baseline characteristics of each group, including age, affected 
side, height, weight, body mass index, and the duration of foot pain, were recorded. Patients were assessed as per Visual Analogue Scale $^{7}$ and Roles-Mandsley score ${ }^{8}$ at the start of treatment and then after $4 \mathrm{wk}$ and 12 week duration on follow up. Results were graded as excellent (0), good (0-30), fair (30-60) and poor (60100) depending on the VAS score and excellent, good, fair and poor on basis of their pain, movements and restriction of activity. To begin with only those patients who were rated as very poor and there symptom were of more than 4 week duration were taken up for study. A lateral X-ray of both heels was taken to demonstrate the presence or absence of a calcaneal spur in painful heel for all cases. $\mathrm{Hb} \%$,
TLC, DLC, ESR, Random Blood Sugar, Serum Uric Acid, and CRP was done in all cases.

PRP preparation and application ${ }^{9}$

We used a double centrifugation technique to concentrate platelets from autologous blood and activated them using calcium. $25 \mathrm{cc}$ venous blood was centrifugated at $1,800 \mathrm{rpm}$ for $15 \mathrm{~min}$ to separate the erythrocytes, and the second time at $3,500 \mathrm{rpm}$ for $10 \mathrm{~min}$ to concentrate platelets to produce a unit of $3 \mathrm{~mL}$ PRP. Injection was performed by the same investigator. Injections were performed by palpating the maximally tender point with a medial approach when the patients were in prone position with the ankle in a neutral position. Patients were blind for the agent used in the treatment. After the procedure, patients were instructed to apply ice to the injected area if needed for pain control in addition to elevation of the limb. Following injection, patients were not allowed weight bearing for 3 days. They were advised to wear comfortable shoes and avoid all running and other high impact activities for 10 days

Data Analysis: The data was analysed by using SPSS for Windows (version 10.0) by applying the ChiSquare test and p-values of 0.05 and less were considered as significant.

\section{Results}

Total 90 patients are included in study. 46 were male and 44 female. 44 patients had complaint in right foot.

\begin{tabular}{|l|c|c|c|}
\hline Characteristics & $\begin{array}{c}\text { Conservative } \\
\text { treatment }\end{array}$ & $\begin{array}{c}\text { Steroid } \\
\text { injection }\end{array}$ & $\begin{array}{c}\text { PRP } \\
\text { injection }\end{array}$ \\
\hline Sex M/F & $17 / 13$ & $13 / 17$ & $16 / 14$ \\
\hline $\begin{array}{l}\text { Affected foot } \\
\text { R/F }\end{array}$ & $16 / 14$ & $13 / 17$ & $15 / 15$ \\
\hline
\end{tabular}

The mean age of all patients was 43.4 (range 22-68 years). The mean body mass index of the patients was 45.84 $\mathrm{kg} / \mathrm{m} 2$. The mean duration of symptoms in all of the groups was 4.42 months. There was no significant difference between groups with respect to mean age, body mass index, and the baseline visual analog scale score $(\mathrm{P}>0.05)$.

\begin{tabular}{|l|c|c|c|}
\hline Characteristics & $\begin{array}{c}\text { Conservative } \\
\text { treatment }\end{array}$ & $\begin{array}{c}\text { Steroid } \\
\text { injection }\end{array}$ & $\begin{array}{c}\text { PRP } \\
\text { injection }\end{array}$ \\
\hline Age (in years) & 42.5 & 43.5 & 44.2 \\
\hline Height (in cms) & 162.6 & 170.3 & 168.3 \\
\hline Weight (kg) & 68 & 64 & 59 \\
\hline BMI (kg/m2) & 41.97 & 59.8 & 35.75 \\
\hline $\begin{array}{l}\text { Duration of foot } \\
\text { pain(months) }\end{array}$ & 4.56 & 3.9 & 4.8 \\
\hline
\end{tabular}

In both corticosteroid and PRP-injected groups, the mean VAS score was statistically lower when compared with pretreatment scores $(\mathrm{P}=0.001)$. The mean VAS heel pain scores measured 3 months after treatment were 3.2 in conservative management,3.4 in the steroid group and 3.6 in the PRP group, and the scores in both groups were significantly lowered when compared with pretreatment levels (7.3 in conservative management, 7.5 in the steroid group and 7.99 in the PRP group) (Table 2).

\begin{tabular}{|l|l|l|l|l|}
\hline \multicolumn{1}{|c|}{ Group } & No. & \multicolumn{3}{c|}{ VAS score (mean) } \\
\hline & & Baseline & $\begin{array}{c}\text { At 4 } \\
\text { weeks }\end{array}$ & $\begin{array}{c}\text { At 12 } \\
\text { weeks }\end{array}$ \\
\hline $\begin{array}{l}\text { Conservative } \\
\text { management }\end{array}$ & 30 & 7.3 & 5.4 & 3.2 \\
\hline Steroid injection & 30 & 7.5 & 4.8 & 3.4 \\
\hline PRP injection & 30 & 7.9 & 5.2 & 3.6 \\
\hline
\end{tabular}

In the evaluation of the patient satisfaction according to the modified criteria of the Roles and Maudsley scores measured 6 months after treatment, it was seen that only four patients $(13.3 \%)$ had poor results in both injection groups (Table 3 ). 


\begin{tabular}{|l|l|c|c|c|c|}
\hline & & \multicolumn{4}{|c|}{ Modified Roles-Maudsley score } \\
\hline & & Excellent & Good & Fair & poor \\
\hline 4 Weeks & & 2 & 18 & 8 & 2 \\
\hline & $\begin{array}{l}\text { Conservative } \\
\text { management } \\
(\mathrm{n}=30)\end{array}$ & 3 & 17 & 7 & 3 \\
\hline & $\begin{array}{l}\text { Steroid injection } \\
(\mathrm{n}=30)\end{array}$ & 2 & 10 & 15 & 3 \\
\hline & $\begin{array}{l}\text { PRP injection } \\
(\mathrm{n}=30)\end{array}$ & 6 & 12 & 9 & 3 \\
\hline & $\begin{array}{l}\text { Conservative } \\
\text { management }\end{array}$ & 8 & 14 & 7 & 1 \\
\hline & Steroid injection & 9 & 12 & 7 & 2 \\
\hline & PRP injection & & & & \\
\hline
\end{tabular}

There was no significant difference between the steroid and PRP groups in the visual analog scale scores and the modified criteria of the Roles and Maudsley scores measured at 4 weeks and 3 months $(P>0.05)$. No complications attributable to PRP and corticosteroid injections were observed.

\section{Discussion}

Plantar fasciitis is poorly understood and believed to be self limitng pathology. The etiology of this condition is not clearly understood and is probably multi-factorial in nature. Weight gain, occupationrelated activity, anatomical variations, poor biomechanics, overexertion, and inadequate footwear are contributing factors ${ }^{10}$.

Ozdemir et $\mathrm{al}^{11}$ demonstrated direct relationship between duration of heel pain and thickness of heel pad. He also showed As spur size increased, the heel pad compression index value increased.

It is widely believed that plantar fasciitis results from repeated microtrauma due to overuse, which results in microtears of the tissue substance until a macro injury occurs. Lemont et al. ${ }^{2}$ concluded that plantar fasciitis is not an inflammatory process but a degenerative process . It is characterized by microtears and necrosis of the plantar fascial ligament and intrinsic necrosis muscles of the foot at their attachments on the calcaneus. Similarly, a study by Snider et al. ${ }^{12}$ showed that the histologic examination of surgical biopsy specimens showed collagen necrosis, angiofibroblastic hyperplasia, chondroid metaplasia, and matrix calcification. Again, no cellular proof of an inflammatory response was cited.

Various method were described for its treatment including change in lifestyle modifications, shoe modification, arch support and orthotics, stretching and strengthening, splinting and walking cast, antiinflammatory, local steroids injection and extra corporeal shock wave therapy and surgery. Local platelet rich plasma injection recently used in pathology of tendinitis. ${ }^{10}$

Gill et $a l^{13}$ evaluated efficacy of various conservative treatment in 411 patients. Each patient completed an outcomes assessment survey instrument that ranked effectiveness of various nonsurgical treatment modalities. He listed the treatment modalities with short leg walking cast, steroid injection, rest, ice, runner's shoe, crepe-soled shoe, aspirin or nonsteroidal anti-inflammatory drug, heel cushion, low-profile plastic heel cup, heat, and Tuli's heel cup in descending order. Dimou, et al.14, Basford et al. 15, Crawford and Snaith 16 demonstrated uses various modalities in conservative treatment and show equivocal effective in treatment.

Although Steroid injection is the mainstay for the management of many hyper inflammatory disorders including plantar fascitis. Steroids have been described as altering the ultrasound appearance of plantar fasciitis by reducing plantar fascia thickness and decreasing the incidence of hypoechoic tissue, in addition to improving clinical parameters ${ }^{17}$.A number of complications were noted including planter fascial rupture, planter fat pad atrophy, lateral planter nerve injury secondary to injection, and calcaneal osteomylities. Fascial rupture and fat pad atrophy are especially serious complications. Fascial rupture interrupts the intrinsic windlass mechanism of the foot and can promote further inflammation in the surrounding tissue, thus promoting pain. In addition planter fat pad atrophy diminishes subcalcaneum cushioning, availing the planter fascia to further insult and, hence, more pain. ${ }^{18}$

PRP is the concentration of platelets derived from the plasma portion of centrifuged filtered autologous blood. It includes various growth factors specially platelet-derived growth factors

(PDGF), epidermal growth factor (EGF), vascular endothelial growth factor (VEGF), and transforming growth factor beta (TGF-_) in high amounts. Addition of autologous concentrations of platelets theoretically augment the healing process. ${ }^{19}$

Barrett et $\mathrm{al}^{9}$ reported on the use 
of injectable PRP for the treatment of plantar fasciitis. They hypothesis that injecting PRP into recalcitrant, symptomatic plantar fascia cause a reparative effect leading to a resolution of symptoms, and this technique was termed plantar fasciorraphy. 6 out of 9 subjects achieved complete resolution of symptoms after 2 months. One subject had resolution after a second injection. After 1 year, $77.9 \%$ of the subjects had no symptoms. They also demonstrated that thickness of the plantar fascia were reduced between pre- and postinjection checked by ultrasound.

Lee et $\mathrm{al}^{20}$ in their prospective, randomized, controlled trial compared steroid injection and autologous blood injection in the treatment of plantar fasciitis. They concluded that corticosteroid is superior in terms of speed and probable extent of improvement than intralesional autologous blood injection although it is also effective in lowering pain and tenderness in chronic plantar fasciitis.

Say et $\mathrm{al}^{21}$, Mahindra et $\mathrm{al}^{22}$ demonstarated that PRP Injection provide better relief in pain and symptoms than local steroid injection.

Ertuğrul Akşahin et $\mathrm{al}^{23}$ studied 60 patients with plantar fasciitis showed that although mean VAS score improves with both steroid and PRP injection, there was no here was no significant difference between steroid and PRP groups in visual analog scale scores and modified criteria of the Roles and Maudsley scores measured at 3 weeks and 6 months.

In our study, we compare the results of patients with chronic plantar fasciitis treated with conservative treatment, local corticosteroid injection and local PRP injection. The evaluation of patient satisfaction rated by the mean VAS score and modified criteria of the
Roles and Maudsley scores measured at 4 week and 3 months after treatment and it revealed that six out of ninty patients $(6.66 \%)$ out of all three groups had poor results. Satisfactory results were achieved with all three treatment methods. Although it also showed that there was no statistically difference in outcome of any of three modalities.

\section{Conclusion}

As all three treatment modalities are at par on comparison of their treatment outcome, there was no preferences to what modalities should be preferred over another. Since conservative method involve less invasive treatment, it should be tried first before shifted to another modalities.

\section{References}

1. Solomon L, Warwick D, Nayagam S. Apley's System of Orthopaedics and Fractures, 9th Edition. London. Hodder Arnold 2010; Chapter 21: The Ankle and Foot. 618-19

2. Lemont H, Ammirati KM, Usen N (2003) Plantar fasciitis: a degenerative process (fasciosis) without inXammation. J AmPodiatr Med Assoc 93:234-237

3. Alan C, League. Current Concepts Review: Planter Fascities. Foot \& Ankle International. 2008;29(3):358-65

4. Lynch DM, Goforth WP, Martin JE, Odom RD, Preece CK, Kotter MW (1998) Conservative treatment of plantar fasciitis: a prospective study. J Am Podiatr Med Assoc 88:375-380

5. KÂter E, Çelikbao E, Akkaya S, Demirkan F, Kiliç BA (2006) Comparison of injection modalities in the treatment of plantar heel pain: a randomized con- trolled trial. J Am Podiatr Med Assoc 96:293-296

6. Soomekh DJ (2011) Current concepts for the use of platelet-rich plasma in the foot and ankle. Clin Podiatr Med Surg 28:155-170

7. D. Gould et al. Visual Analogue Scale (VAS). Journal of Clinical Nursing 2001; 10:697-706

8. Roles NC, Maudsley RH. Radial tunnel syndrome: resistant tennis elbow as a nerve entrapment. J Bone Jt Surg Br 54:499-508

9. Barrett S, Erredge S (2004) Growth factors for chronic plantar fasciitis? Podiatry Today 17:3742

10. Roxas M. Plantar fasciitis: diagnosis and therapeutic considerations Altern Med Rev. 2005 Jun;10(2):83-93

11. Ozdemir H, Soyuncu Y, Ozgorgen M, Dabak K. Effects of changes in heel fat pad thickness and elasticity on heel pain. Journal of the American Podiatric Medical Association. 2004;94(1): 47-52.

12. Snider MP, Clancy WG, McBeath AA (1983) Plantar fascia release for chronic plantar fasciitis in runners. Am J Sports Med 11:215219

13. Gill LH, Kiebzak GM (1996) Outcome of nonsurgical treatment for plantar fasciitis. Foot Ankle Int 17:527-532

14. Dimou ES, Brantingham JW, T Wood. A randomized controlled trial (with blinded observer) of chiropractic manipulation and Achilles stretching vs. orthotics for the treatment of plantar fasciitis. J Am Chiro Assoc 2004; 41(9):32-42.

15. Basford JR et al. A randomized controlled evaluation of lowintensity laser therapy: plantar fasciitis. Arch Phys Med Rehabil 
1998; 79(3):249-254.

16. Crawford F, Snaith M. How effective is therapeutic ultrasound in the treatment of heel pain? Ann Rheum Dis 1996; 55:265-267.

17. Genc H, Saracoglu M, Nacir B, Erdem HR, Kacar M (2005) Long term ultrasonographic follow-up of plantar fasciitis patients treated with steroid injection. Jt Bone Spine 72:61-65

18. Tatli Y, Kapasi S. The real risks of steroid injection for plantar fasciitis, with a review of conservative therapies. Curr Rev Musculoskelet Med (2009) 2:3-9

19. Soomekh DJ (2011) Current concepts for the use of platelet-rich plasma in the foot and ankle. Clin Podiatr Med Surg 28:155-170

20. Lee TG, Ahmad TS (2007) Intralesional autologous blood injection compared to corticosteroid injection for treatment of chronic plantar fasciitis. A prospective, randomized, controlled trial. Foot Ankle Int 28:984-990)

21. Ferhat SAY, Deniz GÜRLER, Erkan İNKAYA, Murat BÜLBÜL. Comparison of plateletrich plasma and steroid injection in the treatment of plantar fasciitis Acta Orthop Traumatol Turc 2014;48(6):667-672

22. Mahindra P, Yamin M, Harpal S. Selhi et alChronic Plantar Fasciitis: Effect of Platelet-Rich Plasma, Corticosteroid, and Placebo. Orthopedics. 2016;39(2):e285e289

23. Akşahin E, Doğruyol D, Yuksel HY, Hapa O, Doğan O, Celebi L, et al. The comparison of the effect of corticosteroids and platelet-rich plasma (PRP) for the treatment of plantar fasciitis. Arch Orthop Trauma Surg 2012;132:781-5. 